\title{
Medialization Laryngoplasty Implant Complication: Endolaryngeal Extrusion
}

\author{
Andrew James MacDonald ${ }^{1}$, Benjamin van der Woerd $^{2}$, Kevin Fung ${ }^{2}$ \\ ${ }^{1}$ Schulich School of Medicine and Dentistry, Western University, Canada; ${ }^{2}$ Department of Otolaryngology, Head \& Neck Surgery, \\ Schulich Medicine \& Dentistry, Western University, London Health Sciences Centre, Victoria Hospital, London, Ontario, Canada.
}

\section{Corresponding Author: \\ Dr Kevin Fung \\ Email: kevin.fung@lhsc.on.ca}

This is an Open Access article distributed under the terms of the Creative Commons Attribution License (creativecommons.org licenses/by/3.0).

Received : February 25, 2020

Accepted : July 15, 2021

Published : August 30, 2021

\begin{abstract}
Background: In this case study, we describe a late complication of a Montgomery ${ }^{\circledR}$ medialization thyroplasty that has not been previously reported, and the surgical approach used for its intervention. Case Report: A 57-year-old gentleman who underwent a medialization laryngoplasty with a Montgomery ${ }^{\circledR}$ implant 3 years previously to treat idiopathic left sided vocal fold paralysis presented with sudden dysphonia following a robust coughing fit. His implant was observed extruding into the endolaryngeal lumen. Revision surgery consisted of implant removal through a transcervical approach and reconstructing the paraglottic space with fibrin glue (Tissel ${ }^{\circledR}$ ) and an autologous free fat graft. Post-operative airway and voice outcomes were excellent, and the patient was decannulated prior to discharge. One-month post-operative voice outcomes were modest [Voice handicap index $(\mathrm{VHI})-10=30$ ]. Conclusion: This report describes a previously unreported complication of medialization thyroplasty of an intraluminal extrusion of a Montgomery implant and a novel surgical approach for repair.
\end{abstract}

Keywords: Dysphonia, Hoarseness, Laryngoplasty, Prostheses and Implants, Vocal Cord Paralysis.

\section{Introduction}

Medialization, or type 1 thyroplasty, has become a common long-term treatment for unilateral vocal fold paralysis. The Montgomery ${ }^{\circledR}$ Thyroplasty Implant System (Boston Medical Products, Shrewsbury, MA) is commonly used in particular for its simplicity, effectiveness, and relatively low chance of complication [1-3]. From the most recent review of Montgomery ${ }^{\circledR}$ medialization thyroplasty procedures, $80 \%$ cases reported no adverse events or complications. Common adverse events included failed implantation, difficulties stabilizing the implant, dyspnea, hematoma, and extra-laryngeal extrusions [3]. This case study was written following CARE guidelines [4], and examines the first documented endotracheal extrusion by a Montgomery ${ }^{\circledR}$ medialization thyroplasty implant, and the novel surgical approach to address this uncommon problem.

\section{Case Report}

In September 2015, a 53-year-old man presented to the otolaryngology service with dysphonia and a pre-operative diagnosis of left vocal fold immobility. He was initially treated with a left vocal fold augmentation procedure using Radiesse gel, and the patient was quite satisfied with the result. Approximately 9 months later, the patient returned following the resorption of the implant material and was interested in a more permanent treatment for his dysphonia. He subsequently underwent a left medialization thyroplasty using a size 12 Montgomery ${ }^{\circledR}$ implant without complications. In June 2019, the patient returned once more with a sudden onset of dysphonia following a massive coughing fit due to an upper respiratory tract infection. A laryngoscopic examination was performed and the Montgomery ${ }^{\circledR}$ 
thyroplasty implant was found partially intruding into the endolaryngeal lumen. Despite this, the displacement seemed to have no effect on the airway [Fig.1].

A subsequent CT scan showed the implant at the level of the glottis, with the medial tip extending into the lumen, consistent with the laryngoscope image. There were no notable diagnostic challenges. The patient was soon taken into the operating room to remove the implant. An awake tracheostomy was performed in order to secure the airway. Subplatysmal fat was concurrently harvested for the free fat graft to be used to reconstitute the paraglottic space. General anesthesia was induced. A transcervical approach was then undertaken to approach the thyroid cartilage. The previous thyroplasty window was identified and defined. The implant was dissected free of the paraglottic space and removed atraumatically, leaving behind a dense fibrous capsule [Fig.2].

The mucosa in the paraglottic space appeared healthy other than a small laceration on the luminal side of the glottis, which was sealed by $0.5 \mathrm{~mL}$ of fibrin sealant $\left(\right.$ Tisseel ${ }^{\circledR}$, Baxter Corporation, Mississauga, ON) injected through the thyroplasty window. The previously harvested fat graft was prepared and inserted into the paraglottic space, partially medializing the left vocal fold. A videolaryngoscope (Glidescope ${ }^{\circledR}$, Verathon Inc, Bothell, WA) was used to visualize the airway and ensure the glottal repositioning would not cause airway symptoms [Fig.3]. The incision was then closed over a passive drain, the anesthetic was reversed, and the patient was admitted for observation.

Post-operatively, the patient had no airway symptoms, and was decannulated after five days. There was a perceptually decent voice improvement as well. The patient was then followed-up onemonth post-operation. Direct laryngoscopy at that time revealed mild atrophy of the fat graft compared to the time of surgery and a moderate voice outcome (VHI-10 = 30).

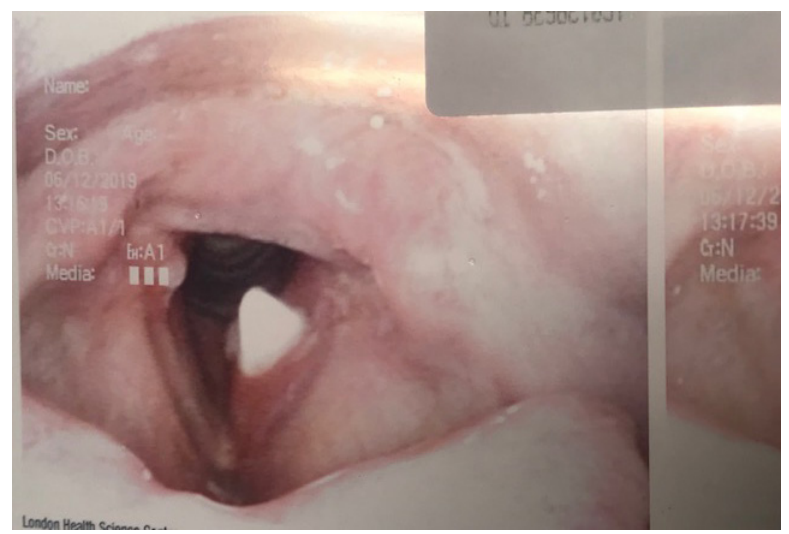

Fig.1: Laryngoscopic image of Montgomery ${ }^{\circledR}$ thyroplasty implant intruding through the glottis into the endolaryngeal lumen.

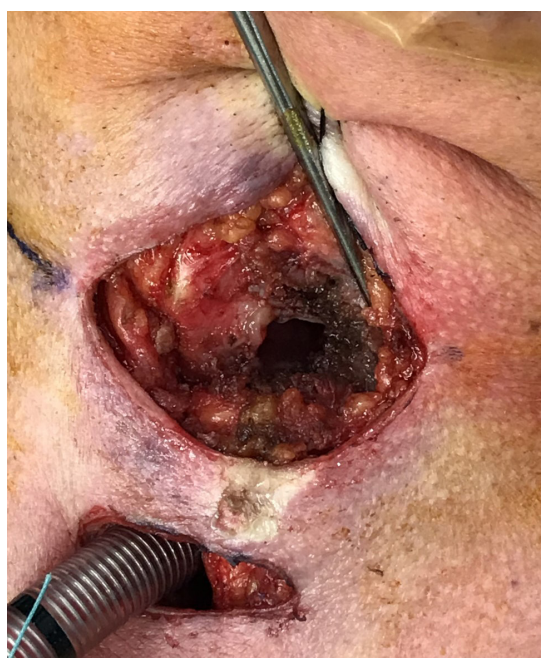

Fig.2: Intra-operative photo of the empty paraglottic space.

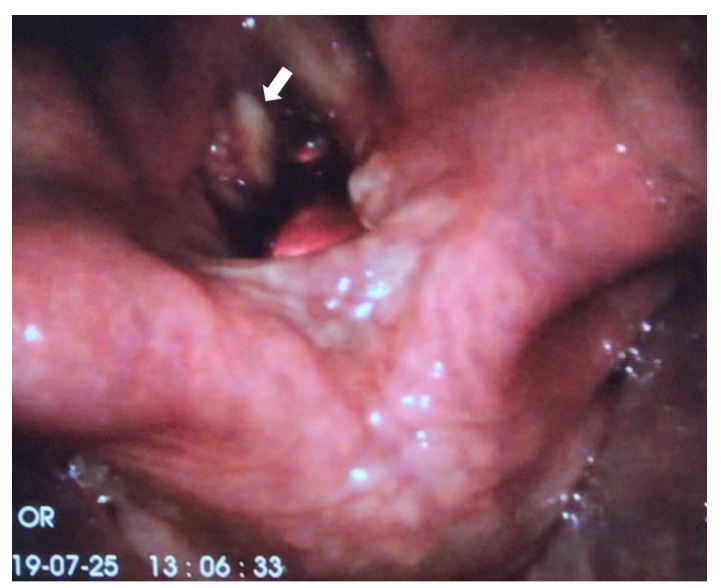

Fig.3: Post-operative laryngoscopic image of the free fat graft (arrow) filling the previously empty glottic space. 


\section{Discussion}

Unilateral vocal cord paralysis has multiple well-established methods of treatment including medialization thyroplasty and injection laryngoplasty [5]. Although the latter has been shown to be more cost effective with similar outcomes as the former, the effects can diminish as the calcium hyrdroxylapatite is absorbed into the body, requiring repeat or alternate interventions such as medialization thyroplasty [6]. Medialization thyroplasties are generally safe with few incidents of adverse events [3]. Endolaryngeal extrusions have been reported as complications in medialization thyroplasty [7-10]. However, these have occurred with implants such as Gore-Tex ${ }^{\circledR}$ and Vocom ${ }^{\circledR}$ and has never been documented in literature using a Montgomery ${ }^{\circledR}$ implant. The authors hypothesize that this could be due to the large external flange that protects against proximal displacement into the lumen. Although endolaryngeal extrusion has not yet been documented with the Montgomery ${ }^{\circledR}$ Thyroplasty System, extra-laryngeal extrusion has been reported [3]. This complication, while less severe is more common. This could be due to the smaller size of the internal flange $[3,11]$. Management for these cases include revision in medialization thyroplasty and injection of silicone rubber under general anesthetic [3].

In context of this case, removal of the stent was performed to avoid any concern surrounding a foreign body reaction that may have contributed to stent extrusion. To fill the large fibrous capsule left by the implant and medialize the vocal fold, a free fat graft was performed.

\section{Conclusion}

This is the first known documented endolaryngeal extrusion complication for a Montgomery ${ }^{\circledR}$ medialization thyroplasty, and thus the complication is likely rare. A free fat graft using autologous fat was performed with success to reconstitute the paraglottic space. Otolaryngologists should be aware of this potential complication and subsequent surgical solution.

Contributors: AJM: manuscript writing, manuscript editing, research, data collection, and literature review; BvW: study inception, manuscript editing, and data collection; KF: study inception, data collection, and manuscript editing. KF will act as a study guarantor. All authors approved the final version of this manuscript and are responsible for all aspects of this study.

Funding: None; Competing interests: None stated.

\section{References}

1. Montgomery WW, Montgomery SK. Montgomery thyroplasty implant system. Ann Otol Rhinol Laryngol Suppl. 1997;170:1-16.

2. McLean-Muse A, Montgomery WW, Hillman RE, Varvares M, Bunting G, Doyle P, et al. Montgomery ${ }^{\circledR}$ Thyroplasty Implant for vocal fold immobility: phonatory outcomes. Ann Otol Rhinol Laryngol. 2000;109:393-400.

3. Laccourreye O, Benkhatar H, Ménard M. Lack of adverse events after medialization laryngoplasty with the montgomery thyroplasty implant in patients with unilateral laryngeal nerve paralysis. Ann Otol Rhinol Laryngol. 2012;121:701-707.

4. CARE Case Report Guidelines. Available from: http:// www.care-statement.org/. Accessed April 27, 2017.

5. Siu J, Tam S, Fung K. A comparison of outcomes in interventions for unilateral vocal fold paralysis: A systematic review. The Laryngoscope. 2016;126:16161624.

6. Tam S, Sun H, Sarma S, Siu J, Fung K, Sowerby L. Medialization thyroplasty versus injection laryngoplasty: a cost minimization analysis. J Otolaryngol - Head Neck Surg. 2017;46.

7. Morris J, Thomas DM. Delayed airway extrusion of type 1 thyroplasty Gore-Tex implant. BMJ Case Rep. 2016;2016.

8. Krane NA, Hu A, Sataloff RT. Gore-Tex extrusion following type I thyroplasty. Ear Nose Throat J. 2016;95:138-140.

9. Watanabe K, Hirano A, Honkura Y, Kashima K, Shirakura M, Katori Y. Complications of using Gore-Tex in medialization laryngoplasty: case series and literature review. Eur Arch Oto Rhino Laryngol. 2019;276:255-261.

10. Mastronikolis NS, Remacle M, Kiagiadaki D, Lawson G, Bachy V, Van Der Vorst S. Medialization thyroplasty for voice restoration after transoral cordectomy. Eur Arch Oto-Rhino-Laryngol. 2013;270:2071-2078.

11. Ayala MA, Patterson MB, Bach KK. Late displacement of a Montgomery thyroplasty implant following endotracheal intubation. Ann Otol Rhinol Laryngol. 2007;116:262-264. 